Jeong Min Lee Joon Koo Han Se Hyung Kim Jae Young Lee Hee Sun Park Hong Eo

Byung Ihn Choi

\section{Radiofrequency ablation in the liver using two cooled-wet electrodes in the bipolar mode}

Published online: 12 August 2005

(C) Springer-Verlag 2005

The online version of the original article can be found at http://dx.doi.org/10.1007/s00330-005-2713-1

J. M. Lee $(\bowtie) \cdot$ J. K. Han · S. H. Kim · J. Y. Lee · H. S. Park

H. Eo · B. I. Choi

College of Medicine-Radiology, Seoul National University,

28 Yongon-Dong, Chongno-gu,

Seoul, 110-744, South Korea

e-mail: leejm@radcom.snu.ac.kr

Tel.: +82-2-7603157

Fax: $+82-2-7436385$

\section{Eur Radiol (2005) s00330-005-2713-1}

Unfortunately, the authors were listed in the incorrect order. The correct order of authors and corresponding author should be as given above. 